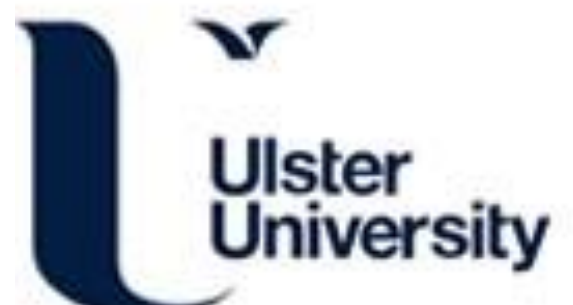

\section{Hierarchical bi-dimensional alumina/palladium nanowire nano-architectures for hydrogen detection, storage and controlled release}

Fang, J., Levchenko, I., Lu, X., Mariotti, D., \& Ostrikov, K. (2015). Hierarchical bi-dimensional alumina/palladium nanowire nano-architectures for hydrogen detection, storage and controlled release. International Journal of Hydrogen Energy, 40(18), 6165 - 6172. https://doi.org/10.1016/j.ijhydene.2015.02.134

Link to publication record in Ulster University Research Portal

\section{Published in:}

International Journal of Hydrogen Energy

Publication Status:

Published (in print/issue): 01/01/2015

DOI:

10.1016/j.ijhydene.2015.02.134

\section{Document Version}

Publisher's PDF, also known as Version of record

\section{General rights}

Copyright for the publications made accessible via Ulster University's Research Portal is retained by the author(s) and / or other copyright owners and it is a condition of accessing these publications that users recognise and abide by the legal requirements associated with these rights.

\section{Take down policy}

The Research Portal is Ulster University's institutional repository that provides access to Ulster's research outputs. Every effort has been made to ensure that content in the Research Portal does not infringe any person's rights, or applicable UK laws. If you discover content in the Research Portal that you believe breaches copyright or violates any law, please contact pure-support@ulster.ac.uk. 


\title{
Hierarchical bi-dimensional alumina/palladium nanowire nano-architectures for hydrogen detection, storage and controlled release
}

\author{
Jinghua Fang ${ }^{a, b}$, Igor Leuchenko ${ }^{a, c, *}$, XinPei Lu ${ }^{d}$, Davide Mariotti ${ }^{e}$, \\ Kostya (Ken) Ostrikov ${ }^{a, c, f}$ \\ a Plasma Nanoscience Laboratories, Manufacturing Flagship, Commonwealth Scientific and Industrial Research \\ Organisation (CSIRO), P.O. Box 218, Lindfield, NSW 2070, Australia \\ b School of Physics, University of Melbourne, Parkville, VIC 3010, Australia \\ c Plasma Nanoscience, School of Physics, The University of Sydney, Sydney, NSW 2006, Australia \\ d State Key Laboratory of Advanced Electromagnetic Engineering and Technology, Huazhong University of Science \\ and Technology, Wuhan, Hubei 430074, People's Republic of China \\ ${ }^{\mathrm{e}}$ Nanotechnology \& Integrated Bio-Engineering Centre (NIBEC), University of Ulster, BT37 OQB, UK \\ ${ }^{f}$ School of Chemistry, Physics, and Mechanical Engineering, Queensland University of Technology, Brisbane, \\ QLD 4000, Australia
}

\section{A R T I C L E I N F O}

\section{Article history:}

Received 30 May 2014

Received in revised form

19 February 2015

Accepted 28 February 2015

Available online 4 April 2015

Keywords:

Palladium nanowires

Hydrogen detection

Storage

\begin{abstract}
A B S T R A C T
We report on the fabrication of bi-dimensional alumina/palladium nanowire nanoarchitectures for hydrogen detection, storage and controlled release. This nanostructured material was fabricated by growing the palladium nanowires directly in the nanosized channels of nanoporous alumina membrane followed by atmospheric-plasma jet treatment to fabricate the interconnected surface structure mostly suitable for hydrogenrelated applications such as controlled release and sensing. Several interesting properties are demonstrated, including high sensitivity levels (up to $0.1 \%$ of $\mathrm{H}_{2}$ in air) and short response times. Large resistance response reaching $100 \%$ for $0.5 \%$ of $\mathrm{H}_{2}$ in air makes it possible to use the fabricated sensors without complex and expensive amplifying circuits. Copyright $\odot$ 2015, Hydrogen Energy Publications, LLC. Published by Elsevier Ltd. All rights
\end{abstract}

reserved.

\section{Introduction}

Cheap, reliable structures and materials capable to detect, store, and controllably release hydrogen are critical elements for many applications ranging from energy conversion devices [1,2] to biotechnology [3], catalysis [4], medicine [5], and hydrogen leak detection [6]. Such materials and structures should satisfy various and sometimes conflicting requirements. For the hydrogen alarm sensors, reliable detection of small leakages and short response times are critical since even very small hydrogen concentrations in an ambient air can lead to ignition $[7,8]$ and explosion $[9,10]$. On the other hand, the biological and medical applications often require slow

\footnotetext{
* Corresponding author. Plasma Nanoscience Laboratories, Manufacturing Flagship, Commonwealth Scientific and Industrial Research Organisation (CSIRO), P.O. Box 218, Lindfield, NSW 2070, Australia.

E-mail address: Igor.Levchenko@csiro.au (I. Levchenko).

http://dx.doi.org/10.1016/j.ijhydene.2015.02.134
}

0360-3199/Copyright @ 2015, Hydrogen Energy Publications, LLC. Published by Elsevier Ltd. All rights reserved. 
controlled release, e.g., to kill cancer cells without damaging ambient tissues [11]. Release of atomic hydrogen could also be important for biological, medical, and other applications $[12,13]$.

Palladium (Pd) is a very promising material for designing various devices for hydrogen-related applications, since it can meet diverse requirements. In particular, it can absorb very large amounts of hydrogen in the form of palladium hydride $\mathrm{PdH}_{\mathrm{x}}$ (when $\mathrm{x}=0.7$, the hydrogen atom density in palladium hydride exceeds that of liquid hydrogen [14]). Hydrogen is released from the Pd surface mainly in the dissociated form [15]. Besides, Pd quickly changes the resistivity in the presence of hydrogen, and thus, it can serve as a sensing element $[16,17]$.

However, many above mentioned parameters fail to keep pace with the rising present-day requirements, and much more should be done to design and fabricate the structure with highly-controllable properties in relation to hydrogen handling. One possible way to enhance the properties of such materials is to use the compound structures involving palladium in combination with various nanostructures, e.g., palladium nanotubes [18], carbon nanotubes covered with palladium nanocrystals [19], Pd-functionalized graphene flakes [20,21], Pd/Sn composites [22] and other sophisticated nanomaterials and nanostructures. One-dimensional palladium nanostructures such as nanowires are among the most promising structures that show highly-promising characteristics [23]. Nevertheless, many parameters should be significantly enhanced for the Pd nanostructures to be used in real applications. For example, the sensitivity levels and rate of response, i.e., the change of the resistance with time still need to be enhanced. Another problem is the stability of Pd nanostructures, which could change their volume significantly during $\mathrm{H}_{2}$ absorption [24] and also crack after desorption. Moreover, for the efficient applications the Pd nanostructures should be arranged into ordered arrays.

The use of hierarchical bi-dimensional nano-architectures involving a dielectric matrix and metal nanostructures could be a promising way to significantly enhance the characteristics of Pd nanowire - based materials for hydrogen handling. Nanoporous materials such as anodized aluminium oxide (AAO) membranes can be used as a base (matrix) for the functional palladium nanowire-based structures [25]. The nanowires in AAO matrix are arranged into a regular hexagonal structure preventing them from touching each other and disturbing the shape and position during the hydrogen absorption-desorption. The channel diameter and length in AAO membranes, and hence the geometry of Pd nanowires can be controlled. Furthermore, the electrical contacts can be fabricated on the surface of AAO membrane. Such structures are relatively cheap and can be made on reasonably large surface areas (up to several $\mathrm{cm}^{2}$ ), but their characteristics still require improvement. Additional plasma-based post-treatment of the hierarchical compound Pd-based materials could significantly enhance the characteristics. Indeed, considerable improvement was obtained by using low-temperature plasmas in designing various nanostructures [26-28]. Microwave [29], radio-frequency [30], arc [31] and magnetron [32,33] discharges are the common systems used for the plasmabased nanofabrication. Among others, atmospheric-pressure plasma jets [34-36] are among the most convenient inexpensive devices that do not require expensive vacuum equipment.

In this paper we report on the fabrication of AAO membrane-based hierarchical Pd nanowire-based bi-dimensional nano-architecture with unusual combination of properties important for the materials for hydrogen-related applications. In particular, these architectures demonstrate high sensitivity (up to $0.1 \%$ of $\mathrm{H}_{2}$ in air can be reliably detected) with a short response time not exceeding $1 \mathrm{~s}$ for $1 \%$ of $\mathrm{H}_{2}$ in air, and large resistance change response reaching $100 \%$ for $0.5 \%$ of $\mathrm{H}_{2}$ in air. The array of Pd nanowires was grown directly on the AAO template and then treated by the atmosphericplasma jet to fabricate the surface structure potentially suitable for hydrogen-related applications such as controlled release and sensing. Our method is cheap, simple, and the fabricated sensors can be used without complex and expensive amplifying circuits.

\section{Experimental details}

A schematic of the fabrication process is shown in Fig. 1. To produce the nanoporous free-standing alumina membranes (to be used as a base matrix for the hierarchical structure), we have used a two-step anodization in an electrochemical anodization cell. A standard voltage-reductional sequence process at a potential of $24 \mathrm{~V}$ DC in sulphuric acid $(0.3 \mathrm{M})$ solution as electrolyte was used [37] (Fig. 1(b)). A thin $(250 \mu \mathrm{m})$ high-purity (99.999\%) aluminium foil was used as a precursor material. The final thickness of the fabricated membrane was $20 \mu \mathrm{m}$. More details on the anodization process can be found elsewhere [38].

The nanoporous membranes with an average pore diameter of about $30 \mathrm{~nm}$ and external diameter of about $10 \mathrm{~mm}$ (Fig. 1(c)) were then immersed in $0.4-0.5 \mathrm{wt} \% \mathrm{PdCl}_{2}$ solution for $24 \mathrm{~h}$ at $0{ }^{\circ} \mathrm{C}$ temperature (Fig. 1(d)). Afterwards, the membranes with $\mathrm{Pd}$ nanowires grown in the channels and $\mathrm{Pd}$ nanoparticles on the membrane surface (Fig. 1(e)) were dried and mounted on the electrode and treated with the atmospheric-plasma jet for $10 \mathrm{~min}$ at a helium flow rate of about $15 \mathrm{~cm}^{3} / \mathrm{s}$ (Fig. 1(f)). The aim of this process is to remove the excessive nanoparticles from the membrane surface, redistribute the remaining nanoparticles and ensure interconnections between the palladium nanowires formed in the membrane channels (Fig. 1(g)). The plasma jet was operated at a frequency of $325-375 \mathrm{kHz}$ and discharge power not exceeding $38 \mathrm{~W}$. More details on the atmospheric-pressure jet treatment and setup can be found elsewhere [35]. SEM image of typical Pd nanowires on the surface of AAO membrane partially dissolved in phosphoric acid (0.4 $\left.\mathrm{M} \mathrm{H}_{3} \mathrm{PO}_{4}\right)$ acid is shown on Fig. 1(h).

\section{Results and discussion}

The ready samples were then examined by scanning electron microscopy (SEM) using field-emission scanning electron microscopy (FE-SEM, type Zeiss Auriga) operated at electron beam energy of $1-5 \mathrm{keV}$ with an InLens secondary electron 
(a) Aluminum foil
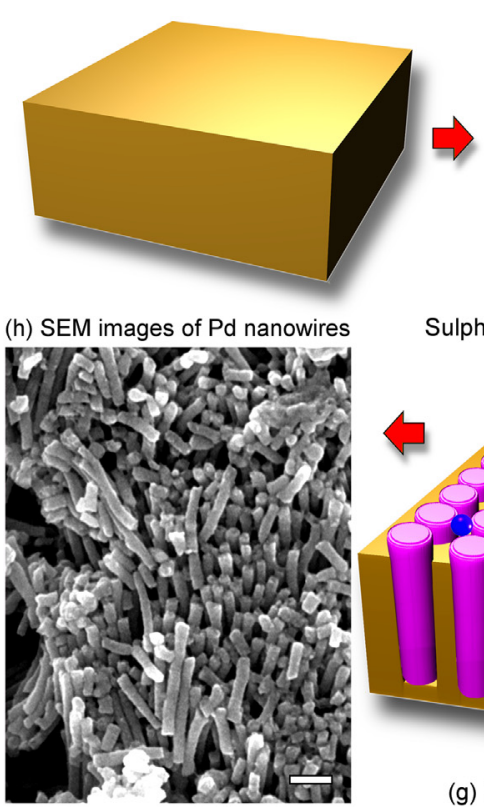

(b) Anodization in sulphuric acid

(c) AAO membrane

(d) Pd deposition from $\mathrm{PdCl}_{2}$

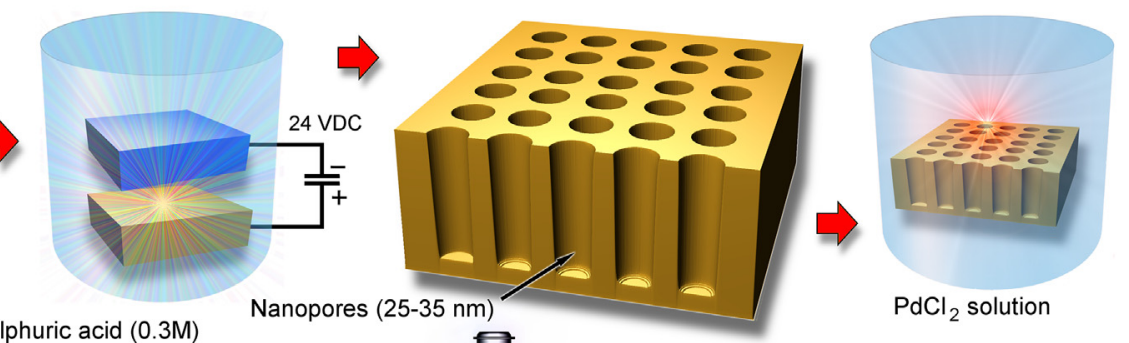

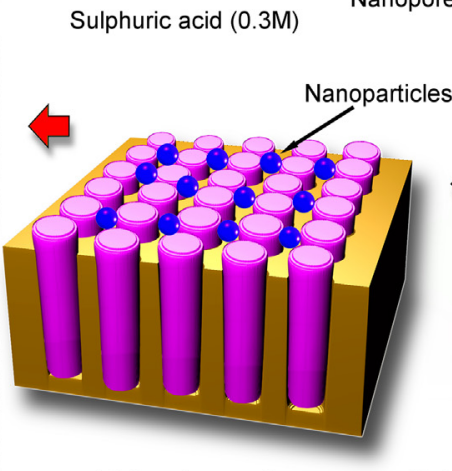

(g) Ready sample

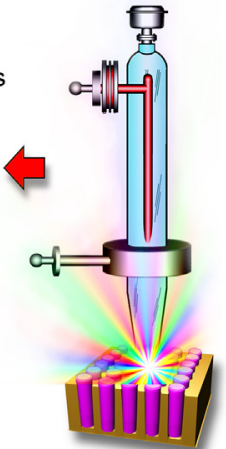

(f) Atmospheric plasma treatment

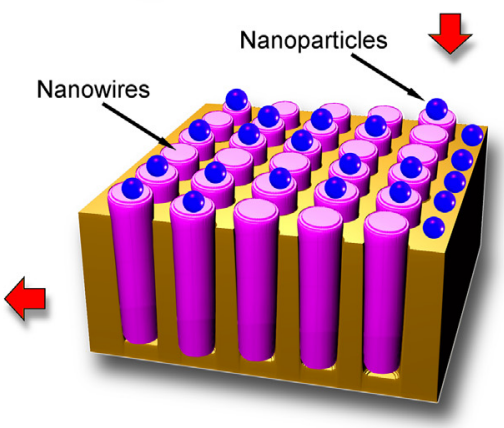

(e) AAO membrane with Pd nanowires

Fig. 1 - Schematic of the process. (a) Aluminium foil ( $250 \mu \mathrm{m}$ thick) is anodized in sulphuric acid (b) to produce AAO membrane (c). Pd nanowires are grown on the ready nanoporous membranes immersed in $\mathrm{PdCl}_{2}$ solution for $24 \mathrm{~h}$ at $0{ }^{\circ} \mathrm{C}$ temperature (d). The membranes with Pd nanowires (e) are subject to plasma pre-treatment (f) to fabricate interconnected surface structure (g). SEM image $(\mathrm{h})$ shows the Pd nanowires after dissolution of the AAO membrane in phosphoric acid. Scale bar is $100 \mathrm{~nm}$.

detector. The structure of the nanowires was studied by the transmission electron microscopy (TEM) using the transmission electron microscope JEOL 2100 operated at electron beam energy of $200 \mathrm{keV}$. Micro-Raman spectroscopy was performed using a Renishaw inVia spectrometer with laser excitations of 514 and $633 \mathrm{~nm}$ at a spot size of $\sim 1 \mu \mathrm{m}^{2}$. Raman spectra from multiple spots were collected to obtain the average statistical characteristics of the samples.

Fig. 2(a) shows the SEM image of the upper surface of the as-prepared nanoporous AAO membrane after anodization.
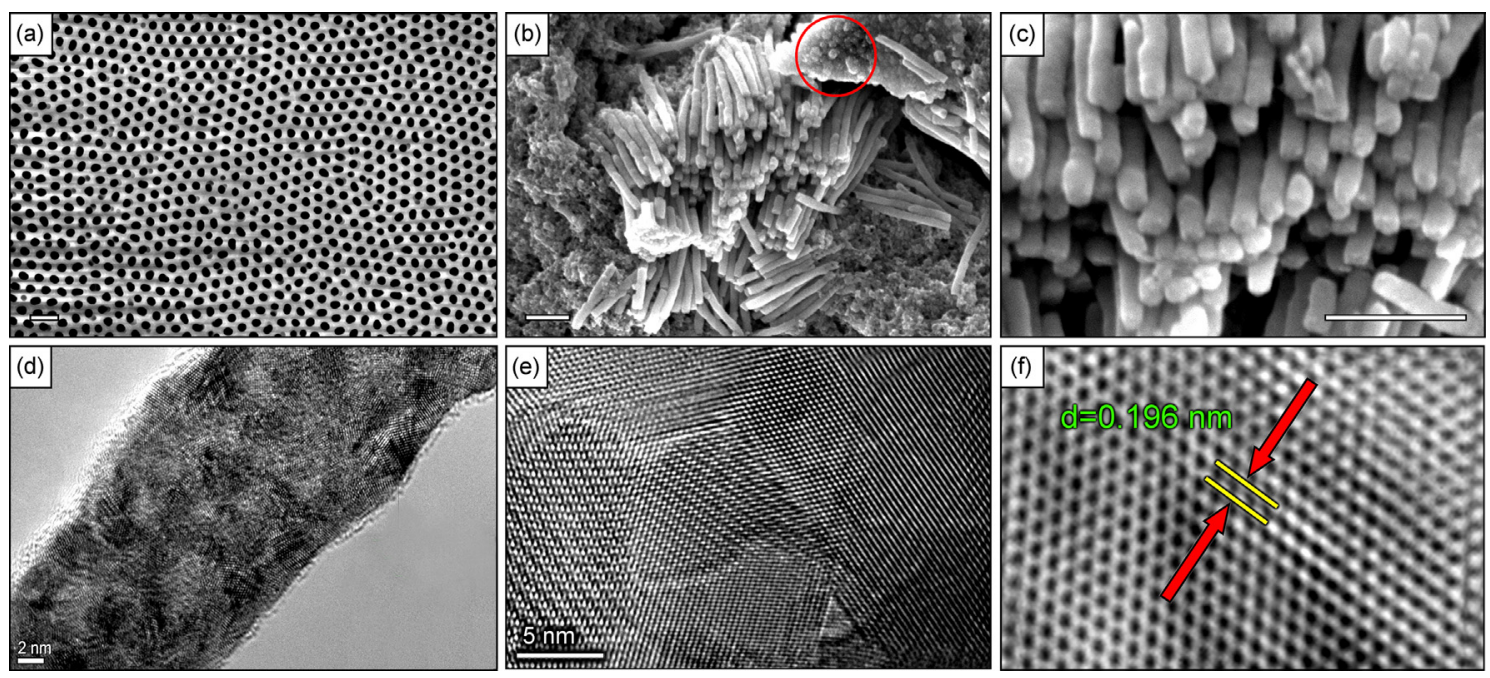

Fig. 2 - Growth of Pd nanowires in the channels of AAO membrane. (a) SEM image of the upper surface (top view) of alumina membrane after anodization. $(b, c)$ Low- and high-resolution SEM images of the palladium nanowires after dissolving the alumina membrane in phosphoric acid. Scale bars are $200 \mathrm{~nm}$. (d, e) HR-TEM images of the Pd nanowire showing its polycrystalline structure. (f) The reversed FFT image of the local area showing the lattice spacing of around $0.196 \mathrm{~nm}$ which corresponds to (200) crystalline face of Pd. 


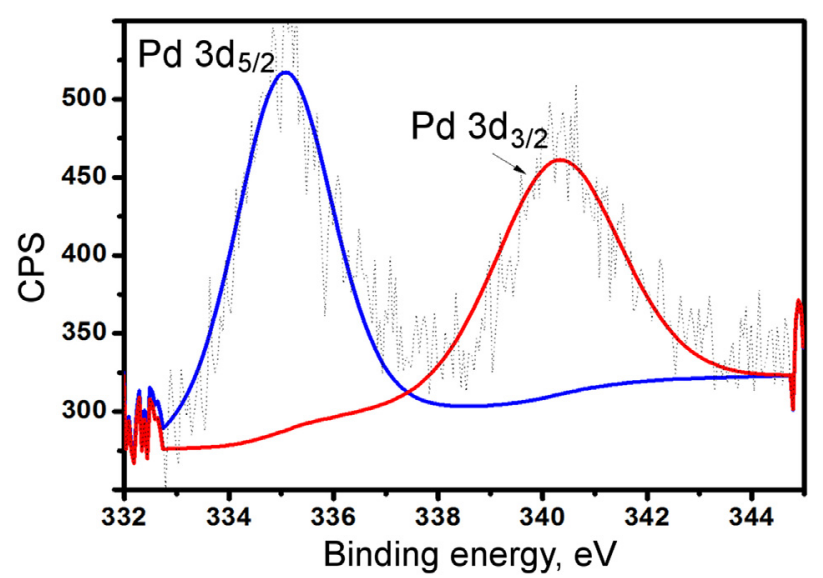

Fig. 3 - XPS spectrum of the grown structure with the two typical Pd peaks.

The $30-\mathrm{nm}$ nanopores are well-organized, the porosity is close to $50 \%$. Further examination shows that the channels piercing the membrane are straight through the whole membrane length. XPS examination (not shown here) of the membrane shows that it is composed of oxygen and aluminium only, i.e., of aluminium oxide $\mathrm{Al}_{2} \mathrm{O}_{3}$. The sizes of nanopores are uniform over the whole surface of sample, i.e., about $1 \mathrm{~cm}^{2}$.

To study the shape, morphology and crystalline structure of the palladium nanowires, we have dissolved the AAO membrane in phosphoric acid. Fig. 2(b) and (c) are the SEM images of the palladium nanowires extracted from the membrane by dissolving. From these images one can see that the nanowires have a length from $500 \mathrm{~nm}$ and sometimes reaching several $\mu \mathrm{m}$, and a diameter of about $20-30 \mathrm{~nm}$, i.e., closely corresponding to an average diameter of the channels in the AAO membrane.

The nanowires are quite straight, not branched and not interconnected. Besides, Pd nanoparticles with the size of 20-30 $\mathrm{nm}$ can be noticed on the surface of partially dissolved AAO membrane (highlighted by red circle on Fig. 2(b)). These nanoparticles were partially melted and evaporated during the plasma treatment, so they are roundish in shape and are uniformly distributed over the surface [39]. More SEM images can be found in the Supplementary Information, Fig. S1.

Fig. 2(d) and (e) are the TEM and high-resolution TEM (HRTEM) images of the nanowire picked up after membrane dissolution. As it follows from the images, the nanowire has a polycrystalline structure which is the most advantageous for sensing application, since this structure ensures an abrupt resistance change due to hydrogen penetration between crystals [40]. An average single crystal size is $5-10 \mathrm{~nm}$. More TEM images can be found in the Supplementary Information, Fig. S2. Fig. 2(f) is the reversed fast Fourier transform (FFT) image of the local area showing the lattice spacing of around $0.196 \mathrm{~nm}$, which corresponds to the (200) crystalline face of Pd. Fig. 3 is the XPS spectra of the grown structure with the two typical Pd peaks.

Let us now examine in detail the effect of the atmosphericjet plasma treatment on the structure and morphology of the fabricated structure. As it was stated above, the as-grown samples (nanoporous membrane with the Pd nanowires and some amount of the Pd nanoparticles on the membrane top) were treated by atmospheric plasma jet, as shown in Fig. 4(a). The jet is rather thin (not exceeding $1 \mathrm{~mm}$ in diameter, see photo of the discharge in Fig. 4(b)), and thus we have scanned the sample surface by moving the sample during the treatment (Fig. 4(a)). An average sample temperature did not noticeably change, but the metal nanoparticles were subject to very high temperature spikes due to their small sizes. As a result, the nanoparticles were partially melted and removed from the surface. Note also that the melting temperature of nanoparticles is significantly lower that of the bulk materials [41].

Fig. 4(c) and (d) show the upper surface of the AAO membrane after Pd nanowire growth and after the plasma treatment, respectively. Small nanoparticles were removed and partially melted, and the interconnections between nanowires sitting in the membrane channels were created by forming a nearly continuous thin Pd film on the AAO surface (and possibly, by partial penetration of palladium into the channels). These interconnections have integrated all nanowires into a single circuit and significantly enhanced the sensitivity of response to ultra-small concentrations of hydrogen, as it was demonstrated by the further measurements.

Fig. 4(e) and (f) show the side views of the block of nanowires extracted from the membrane after the plasma treatment. In this case, the AAO membrane was also dissolved in phosphoric acid. These images also clearly show the interconnections between the nanowire tops. The nanowires are combined into a single block, but do not touch each other by the side surfaces, when they are in the channels of the AAO membrane (which is a dielectric material with a very high specific resistivity). The sample resistance before the plasma treatment was $200 \mathrm{M} \Omega$ and then dropped to only $20 \mathrm{M} \Omega$ after the treatment.

The fabricated Pd nanowire/AAO membrane hierarchical nano-hybrid material was mounted in the test chamber and connected to the measurement circuit. During the measurements of interaction with the hydrogen gas flow, the mixture of air and analyte $\left(\mathrm{H}_{2}\right)$ was passed through the chamber at room temperature (Fig. 5(a)). The sensitivity measurements demonstrate that the fabricated Pd nanowire/AAO membrane nano-hybrid material is very sensitive to hydrogen concentration. Indeed, as one can see in Fig. 5(b), a short (30 s) pulse of hydrogen with the concentration of $0.01 \%$ can be detected. In this case, the resistance change was $20 \%$, i.e. sufficient for the reliable measurement. When the $\mathrm{H}_{2}$ concentration was increased to only $0.05 \%$, the resistance change reached $30 \%$. Importantly, the response time was short in this case, not exceeding $10 \mathrm{~s}$. Finally, detection of higher concentrations of $\mathrm{H}_{2}$ in air $(0.5 \%)$ results in a very short response times not exceeding 1-2 s.

One more important feature is a very high change of resistance when detecting relatively high hydrogen concentrations. Indeed, when detecting $1 \%$ of hydrogen in air, the resistance change was $120 \%$ (Fig. 5(b)). Such a strong response makes it possible to additionally control signalling circuits, i.e., without any additional signal amplifying devices. 

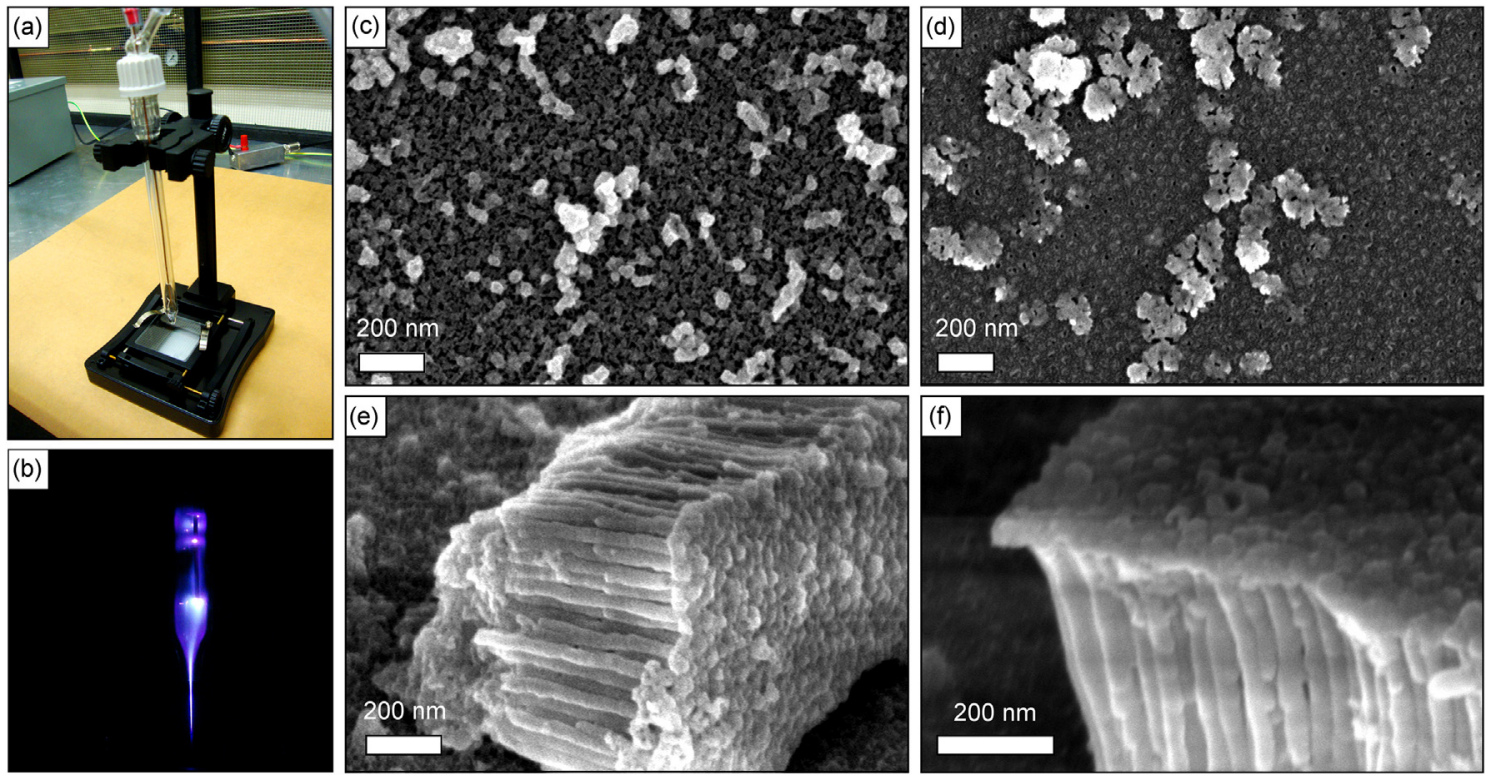

Fig. 4 - Growth of Pd nanowires in the channels of AAO membrane. (a) Photograph of the atmospheric-pressure plasma jet setup with mounted sample and (b) photograph of the atmospheric-pressure plasma jet operated at frequency $325-375 \mathrm{kHz}$ and power $50 \mathrm{~W}$. Upper surface of the AAO membrane after Pd nanowire growth (c) and after the plasma treatment (d). Small nanoparticles were removed and partially melted, and the interconnections between nanowires sitting in the membrane channels were created. Side view of the block of nanowires extracted from the membrane after the plasma treatment (e, $f$ ) show interconnections between the nanowire tops.

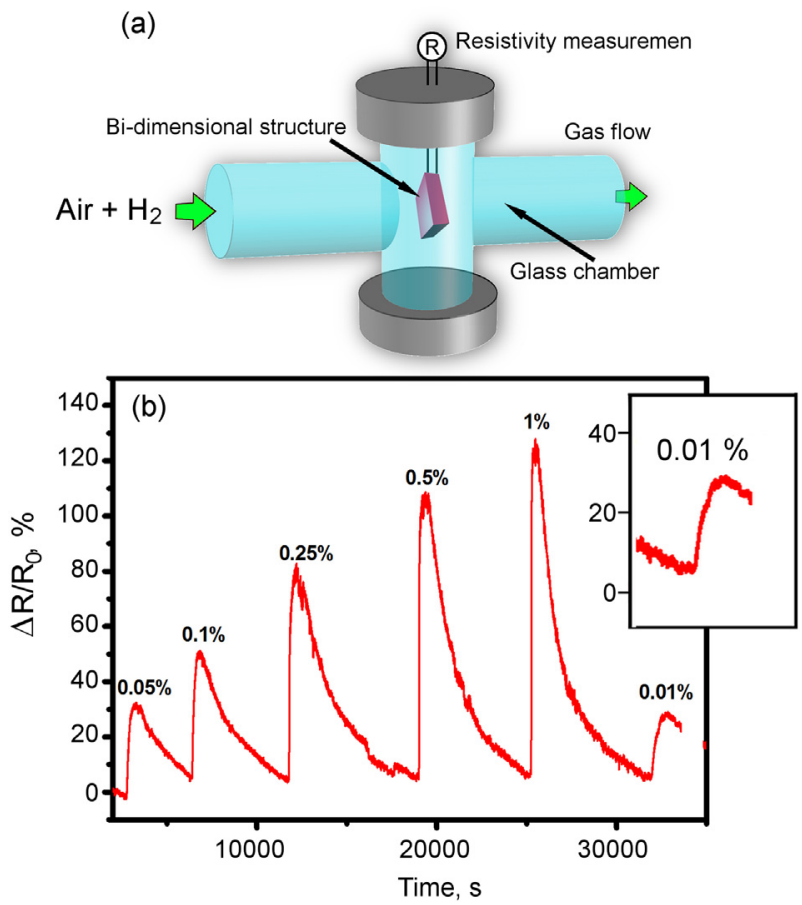

Fig. 5 - Schematic of sensitivity measurements (a) and the response to different percentage of hydrogen in air flow (b). $30 \%$ resistivity change is observed for the ultra-small $(0.01 \%)$ percentage of hydrogen in air.
On the other hand, the recovery time of the fabricated material is quite long. Apparently, this is an intrinsic property of the structure based on the nanoporous membrane, which is based on the quite thick nanoporous membrane, potentially capable of absorbing a very large amount of hydrogen (being a function of alumina thickness which is not limited by the proposed process) and then slowly release it. This feature could be useful for the applications requiring large amounts of hydrogen gradually released over a long time (e.g., for catalytic hydrogen conversion to electricity $[42,43])$. The release of the gas absorbed in nanopores requires considerable time at a room temperature, as it is seen in Fig. 5 (We did not use heating between gas pulses.). This feature limits the use of the structure for the fast detection of changing hydrogen concentrations, but makes it suitable for the application in alarm devices which do not need to be reset immediately after the analyte is detected. Besides, the release time can be effectively controlled by external parameters such as humidity and temperature [44].

Fig. 6(a) shows the dependence of relative change of the resistance on time in the test with several gas pulses and hydrogen concentration $0.1 \%$. After shutting off the gas supply, the resistance of the material starts slow recovery by releasing accumulated gas. Interestingly, it remains ready for the detection of the next gas pulse. The next pulse increases the structure resistivity even more, and the number of pulses can be counted on the resistance/time dependence. Similar measurements conducted for the hydrogen concentration $1 \%$ show comparable results, with the resistance change up to 

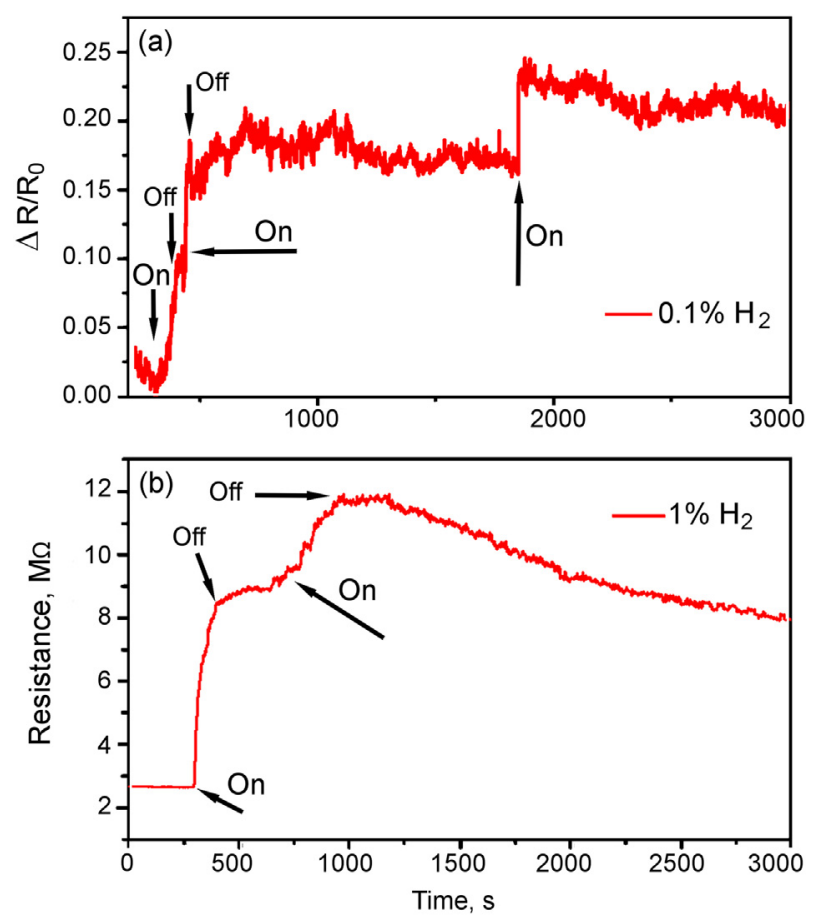

Fig. 6 - (a) Dependence of a relative change of the resistance on time in the test with several gas pulses and hydrogen concentration $0.1 \%$. Due to the very short response time and long recovery time, the structure could perform the function of a pulse counter with memory. (b) Dependence of structure resistance on time in the test with several gas pulses and hydrogen concentration $1 \%$.

$300 \%$ (the change from $2.8 \mathrm{M} \Omega$ to almost $12 \mathrm{M} \Omega$ after the saturation signal is achieved, see Fig. $6(\mathrm{~b}))$.

To directly compare the obtained results with other nano structures, we have designed, fabricated and tested the similar structure on the same platform, i.e. on the nanoporous membrane, but without the palladium nanowires in the pores. Specifically, we have fabricated the nanoporous alumina template and covered it with the palladium layer (by the

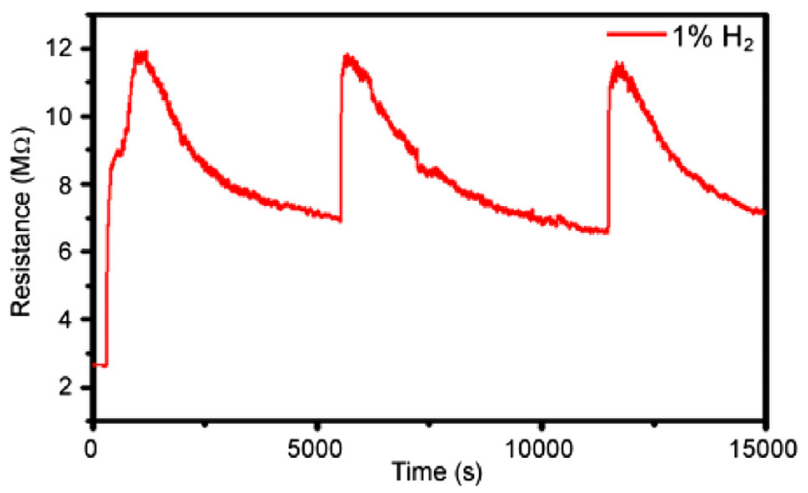

Fig. 8 - (a) Cycling test.

thermal sputtering) on the top, without filling the pores and without blocking the pore openings. Fig. 7 illustrates the fabricated structure and the results of the sensing measurements. The sensitivity and the range of response to hydrogen exposure of this structure are much lower compared to the nano-architecture incorporating the Pd-nanowires (compare with Fig. 5).

To further characterize the fabricated nano-architecture with Pd nanowires, we have made additional tests to demonstrate the system response to the cycling test (Fig. 8). This test has demonstrated that the fabricated platform is capable to the cycling operation, and hence, can be promising for the controlled hydrogen storage/release function.

Long recovery, in combination with very short response times, make it possible to use this material as a device capable to detect and simultaneously accumulate and then slowly release hydrogen, i.e., in medical applications where the low concentrations of $\mathrm{H}_{2}$ should be maintained. It is evident that the plasma-fabricated interconnections between nanowires on the surface of membrane can be a tool for controlling the rate of hydrogen release. The density and morphology of the interconnections can be changed by varying the plasma power and time of the plasma expose. Consequently, the kinetics of hydrogen release can be adjusted.
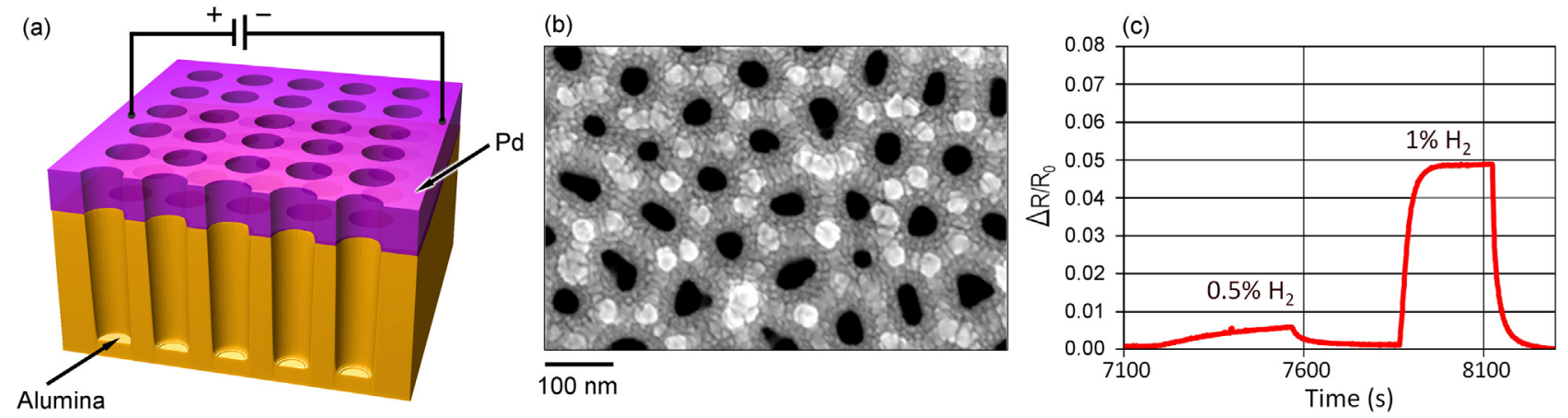

Fig. 7 - Alternative nano-architecture used for an additional sensing test. (a) Sample consisting of nanoporous alumina covered with a thin Pd layer non-blocking the pore openings. (b) SEM images (top view) of the Pd layer on the top of alumina membrane. (c) Results of sensitivity test (resistivity change) of the alternative nano-architecture. The sensitivity is much lower, as compared with Pd-nanowire nano-architecture (compare with Fig. 5). 


\section{Conclusion}

We report on the fabrication and testing of the alumina membrane-based palladium nanowire hierarchical bidimensional nanomaterial which demonstrates properties potentially useful for the hydrogen-handling devices. The structure was enhanced by the atmospheric-plasma jet posttreatment, which made it possible to fabricate the interconnected surface structure on the surface of alumina membrane with the palladium nanowires in the membrane channels. High sensitivity levels reaching $0.01 \%$ of $\mathrm{H}_{2}$ in air and short response times were demonstrated, together with the capability to store hydrogen and release it slowly. Large resistance response reaching $100 \%$ for $0.5 \%$ of $\mathrm{H}_{2}$ in air and $300 \%$ for $1.0 \%$ of $\mathrm{H}_{2}$ makes it possible to use this structure directly in the control devices without complex and expensive amplifying circuits. Further studies on the use of plasma techniques for the fabrication and enhancing complex hierarchical nanomaterials could lead to high-performance hydrogen handling devices.

This work was partially supported by CSIRO's OCE Science Leadership Research Program, CSIRO Julius Career Award, CSIRO Sensors and Sensor Network TCP, CSIRO Julius Award and the Australian Research Council. We thank L. K. Randeniya for the assistance in hydrogen response measurements, and S. Prawer and Z. Han for useful discussions.

\section{Appendix A. Supplementary data}

Supplementary data related to this article can be found at http://dx.doi.org/10.1016/j.ijhydene.2015.02.134.

\section{R E F E R E N C E S}

[1] Cui N, Wu W, Zhao Y, Bai S, Meng L, Qin Y, et al. Magnetic force driven nanogenerators as a noncontact energy harvester and sensor. Nano Lett 2012;12(7):3701-5.

[2] Yang Y, Zhu G, Zhang H, Chen J, Zhong X, Lin ZH, et al. Triboelectric nanogenerator for harvesting wind energy and as self-powered wind vector sensor system. ACS Nano 2013;7(10):9461-8.

[3] Taipale M, Krykbaeva I, Whitesell L, Santagata S, Zhang J, Liu Q et al. Chaperones as thermodynamic sensors of drugtarget interactions reveal kinase inhibitor specificities in living cells. Nat Biotechnol 2013;31:630-7.

[4] Ding K, Liu L, Cao Y, Yan X, Wei H, Guo Z. Formic acid oxidation reaction on a $\mathrm{Pd}_{\mathrm{x}} \mathrm{Ni}_{\mathrm{y}}$ bimetallic nanoparticle catalyst prepared by a thermal decomposition process using ionic liquids as the solvent. Int J Hydrogen Energy 2014;39(14):7326-37.

[5] Ndieyira JW, Kappeler N, Logan S, Cooper MA, Abell C, McKendry RA, et al. Surface-stress sensors for rapid and ultrasensitive detection of active free drugs in human serum. Nat Nanotechnol 2014;9:225-32.

[6] Koper MTM. Hydrogen electrocatalysis: a basic solution. Nat Chem 2013;5:255-6.

[7] Grune J, Sempert K, Kuznetsov M, Breitung W. Experimental study of ignited unsteady hydrogen jets into air. Int J Hydrogen Energy 2011;36(3):2497-504.
[8] Butler MS, Moran CW, Sunderland PB, Axelbaum RL. Limits for hydrogen leaks that can support stable flames. Int $\mathrm{J}$ Hydrogen Energy 2009;34(12):5174-82.

[9] Kim WK, Mogi T, Dobashi R. Fundamental study on accidental explosion behavior of hydrogen-air mixtures in an open space. Int J Hydrogen Energy 2013;38:8024-9.

[10] Paillard CE, Naudet V. Risk assesment for the preparation of compressed oxidant-fuel gas mixtures. Application to the $\mathrm{H}_{2}$ /air mixture manufacturing. Int J Hydrogen Energy 2012;37(22):17336-49.

[11] Lee ZW, Zhou J, Chen C-S, Zhao Y, Tan C-H, Li L, et al. The slow-releasing hydrogen sulfide donor, GYY4137, exhibits novel anti-cancer effects in vitro and in vivo. PLoS One 2011;6(6):e21077.

[12] Zhao Y, Bhushan S, Yang C, Otsuka H, Stein JD, Pacheco A, et al. Controllable hydrogen sulfide donors and their activity against myocardial ischemia-reperfusion injury. ACS Chem Biol 2013;8(6):1283-90.

[13] Wolter M, Levchenko I, Kersten H, Ostrikov K. Hydrogen in plasma-nanofabrication: selective control of nanostructure. Appl Phys Lett 201; 96: 133105.

[14] McMurry JE, Faye RC. Chemistry. 5th ed. Pearson Prentice Hall; 2008.

[15] Mitsui T, Rose MK, Fomin E, Ogletree DF, Salmeron M. Dissociative hydrogen adsorption on palladium requires aggregates of three or more vacancies. Nature 2003; 422:705-7.

[16] Tittl A, Mai P, Taubert R, Dregely D, Liu N, Giessen H. Palladium-based plasmonic perfect absorber in the visible wavelength range and its application to hydrogen sensing. Nano Lett 2011;11(10):4366-9.

[17] Shegai T, Johansson P, Langhammer C, Käll M. Directional scattering and hydrogen sensing by bimetallic $\mathrm{Pd}-\mathrm{Au}$ nanoantennas. Nano Lett 2012;12(5):2464-9.

[18] Yu S, Welp U, Hua LZ, Rydh A, Kwork WK, Wang HH. Fabrication of palladium nanotubes and their application in hydrogen sensing. Cem Mater 2005;17:3445-50.

[19] Randeniya LK, Martin PJ, Bendavid A. Detection of hydrogen using multi-walled carbon-nanotube yarns coated with nanocrystalline Pd and Pd/Pt layered structures. Carbon 2012;50:1786-92.

[20] Esfandiar A, Irajizad A, Akhavan O, Ghasemi S, Gholami MR. $\mathrm{Pd}-\mathrm{WO}_{3} /$ reduced graphene oxide hierarchical nanostructures as efficient hydrogen gas sensors. Int $J$ Hydrogen Energy 2014;39(15):8169-79.

[21] Johnson JL, Behnam A, Pearton SJ, Ural A. Hydrogen sensing using Pd-functionalized multi-layer graphene nanoribbon networks. Adv Mat 2010;22:4877-81.

[22] Jeong SH, Kim S, Cha J, Son MS, Park SH, Kim HY, et al. Hydrogen sensing under ambient conditions using $\mathrm{SnO}_{2}$ nanowires: synergetic effect of $\mathrm{Pd} / \mathrm{Sn}$ codeposition. Nano Lett 2013;13(12):5938-43.

[23] Yang D, Valentín L, Carpena J, Otaño W, Resto O, Fonseca LF. Temperature-activated reverse sensing behavior of Pd nanowire hydrogen sensors. Small 2013;9:188-92.

[24] Wei I, Brewer J. Desorption of hydrogen from palladium plating. AMP J Technol 1996;5:49-53.

[25] Zeng XQ, Latimer ML, Xiao ZL, Panuganti S, Welp U, Kwok WK, et al. Hydrogen gas sensing with networks of ultrasmall palladium nanowires formed on filtration membranes. Nano Lett 2011;11(1):262-8.

[26] Ostrikov K, Neyts EC, Meyyappan M. Plasma nanoscience: from nano-solids in plasmas to nano-plasmas in solids. Adv Phys 2013;62:113-24.

[27] Levchenko I, Ostrikov K, Murphy AB. Plasma-deposited Ge nanoisland films on Si: is Stranski-Krastanow fragmentation unavoidable? J Phys D Appl Phys 2008;41:092001. 
[28] Cvelbar U, Chen Z, Sunkara MK, Mozetič M. Spontaneous growth of superstructure $\alpha-\mathrm{Fe}_{2} \mathrm{O}_{3}$ nanowire and nanobelt arrays in reactive oxygen plasma. Small 2008;4(10):1610-4.

[29] Levchenko, Keidar M, Xu S, Kersten H, Ostrikov K. Lowtemperature plasmas in carbon nanostructure synthesis. J Vac Sci Technol B 2013;31:050801.

[30] Cvelbar U, Markoli B, Poberaj I, Zalar A, Kosec L, Spaić S. Formation of functional groups on graphite during oxygen plasma treatment. Appl Surf Sci 2006;253:1861-5.

[31] Volotskova O, Fagan JA, Huh JY, Phelan FR. Tailored distribution of single-wall carbon nanotubes from arc plasma synthesis using magnetic fields. ACS Nano 2010;4(9):5187-92.

[32] Levchenko I, Romanov M, Keidar M. Investigation of a steady-state cylindrical magnetron discharge for plasma immersion treatment. J Appl Phys 2003;94:14081413.

[33] Levchenko I, Romanov M, Keidar M, Beilis II . Stable plasma configurations in a cylindrical magnetron discharge. Appl Phys Lett 2004;85:2202.

[34] Lu X, Laroussi M. Dynamics of an atmospheric pressure plasma plume generated by submicrosecond voltage pulses. J Appl Phys 2006;100:063302.

[35] Mariotti D, Ostrikov K. Tailoring microplasma nanofabrication: from nanostructures to nanoarchitectures. J Phys D 2009;42:092002.

[36] Levchenko I, Ostrikov K, Mariotti D, Švrček V. Self-organized carbon connections between catalyst particles on a silicon surface exposed to atmospheric-pressure $\mathrm{Ar}+\mathrm{CH}_{4}$ microplasmas. Carbon 2009;47:2379-90.
[37] Fang J, Spizzirri PG, Lin L, Roberts A, Prawer S. Template controlled fabrication of silver nano-structures using porous anodic aluminium oxide. J Aust Ceram Soc 2010;46: $46-51$.

[38] Fang J, Aharonovich I, Levchenko I, Ostrikov K, Spizzirri PG, Rubanov S, et al. Plasma-enabled growth of single-crystalline $\mathrm{SiC} / \mathrm{AlSiC}$ core-shell nanowires on porous alumina templates. Cryst Growth Des 2012;12:2917-22.

[39] Levchenko I, Korobov M, Romanov M, Keidar M. Ion current distribution on a substrate during nanostructure formation. J Phys D Appl Phys 2004;37:1690-5.

[40] Wang G, Ji Y, Huang X, Yang X, Gouma PI, Dudley M. Fabrication and characterization of polycrystalline $\mathrm{WO}_{3}$ nanofibers and their application for ammonia sensing. J Phys Chem B 2006;110(47):23777-82.

[41] Borras A, Sanchez-Valencia JR, Widmer R, Rico VJ, Justo A, Gonzalez-Elipe AR. Growth of crystalline $\mathrm{TiO}_{2}$ by plasma enhanced chemical vapor deposition. Cryst Growth Des 2009;9:2868-76.

[42] Ahluwalia RK, Hua TQ, Peng JK. On-board and off-board performance of hydrogen storage options for light-duty vehicles. Int J Hydrogen Energy 2011;37(3):2891-910.

[43] Bartelsa JR, Pate MB, Olson NK. An economic survey of hydrogen production from conventional and alternative energy sources. Int J Hydrogen Energy 2010;35(16):8371-84.

[44] Cho J-H, Yu J-B, Kim J-S, Sohn S-O, Lee D-D, Huh J-S. Sensing behaviors of polypyrrole sensor under humidity condition. Sens Actuator B 2005;108:389-92. 